\title{
ABSCESO RENAL CON PERFORACIÓN A TÓRAX
}

\author{
E.A. GRANADOS LOARCA, R.E. QUEZADA OCHOA, C.B. SALAZAR MONTERROSO
}

Servicio de Urología. Hospital General de Enfermedades Zona 9. Instituto Guatemalteco de Seguridad Social. IGSS. Guatemala.

Actas Urol Esp. 28 (2): 129-132, 2004

\section{RESUMEN}

\section{ABSCESO RENAL CON PERFORACIÓN A TÓRAX}

OBJETIVO: Presentar un caso de absceso renal secundario a una pielonefritis xantogranulomatosa con perforación a tórax que requirió nefrectomía y decorticación pleural izquierda.

MÉTODOS Y RESULTADOS: Mujer de 38 años que presentó infecciones del tracto urinario secundario a litiasis renal, que evolucionó a un absceso renal que se perforó a tórax donde se formó un absceso. Fue tratada con nefrectomía y drenaje de absceso torácico por tubo intratorácico, y posterior decorticación, con buena evolución.

CONCLUSIONES: El absceso renal y/o la pielonefritis xantogranulomatosa se asocian o son el resultado de una litiasis obstructiva no tratada, que condiciona la aparición de infección urinaria y posterior pionefrosis y o absceso renal. La no-detección temprana del absceso renal condiciona a la perforación a retroperitoneo, intra-abdominal y a tórax. El tratamiento precoz del absceso (antibióticos y drenaje percutáneo) puede evitar la nefrectomía.

PALABRAS CLAVE: Absceso renal. Pielonefritis xantogranulomatosa. Perforación a tórax.

\section{ABSTRACT \\ RENAL ABSCESS WITH CHEST PERFORATION}

OBJECTIVE: To present a case of secondary renal abscess to a xanthogranulomatosis pyelonephritis with perforation to chest that required nephrectomy and decortication left pleural.

METHODS AND RESULTS: Patient feminine of 38 years that present infections from the tract urinary secondary to kidney lithiasis that evolve to a kidney abscess that you perforates to chest where you forms an abscess. It was treated with nephrectomy and drainage of chest abscess by chest tube, and later decortication, with good evolution.

CONCLUSIONS: The kidney abscess and/or xanthogranulomatosis pyelonephritis are the result of a lithiasis not treated obstruction that conditions to the appearance of urinary infection and posterior pyonephrosis and or kidney abscess. The not early detection of the kidney abscess conditions to the perforation to retroperitoneal, intrabdominal and to chest. The early treatment of the abscess (antibiotics and percutaneous drainage) it can avoid the nephrectomy.

WORDS KEY: Kidney abscess. Xanthogranulomatosis pyelonephritis. Perforation chest. 
$\mathrm{E}_{\mathrm{p}}^{\mathrm{l}}$ absceso renal es una colección de material purulento confinado al parénquima renal y que se localiza en la corteza, éste puede ser secundario a una pielonefritis xantogranulomatosa. La obstrucción parcial del riñón hace que refluya orina infectada al riñón, 2/3 de los abscesos se asocian a litiasis renal y daño renal, como sucedió en este caso. Se presenta un caso de absceso renal con perforación a pulmón que requirió nefrectomía y decorticación del pulmón izquierdo.

\section{CASO CLÍNICO}

Mujer de 38 años de edad, que acudió por dolor abdominal de 3 meses de evolución. La paciente inicia dolor a nivel del flanco y fosa renal izquierda, asociado a náuseas, por lo que consulta al médico, quién le efectuó U.I.V y ultrasonido renal, observándose cálculo piélico del lado izquierdo por lo que es tratada con antiespasmódicos. La paciente se siente bien por lo que no acude al Centro Hospitalario; 3 meses después inicia cólico nefrítico con las mismas características, asociado a náuseas y fiebre de $40^{\circ} \mathrm{C}$ por lo que acude al Centro Hospitalario. La paciente acude en mal estado, deshidratada, fiebre $39,5^{\circ} \mathrm{C}$, frecuencia cardíaca de 112 por minuto, frecuencia respiratoria de 24 por minuto; se ausculta hipoventilación basal pulmonar izquierda; abdomen globoso, se palpa tumefacción y presenta dolor en flanco e hipocondrio izquierdo, no signos de irritación peritoneal. Laboratorio: leucocitosis 22,100, $83 \%$ segmentados, $\mathrm{Hb} 9,5 \mathrm{~g} / \mathrm{dl}$, Ht 27\%, creatinina $1,4 \mathrm{mg} / \mathrm{dl}$, leucocituria campos llenos, nitritos + , proteína 100 $\mathrm{mg} / \mathrm{dl}$, eritrocituria 15-20 por campo. La radiografía de tórax demostró borramiento del ángulo costo diagramático izquierdo por nivel líquido (Fig. 1). La radiografia de abdomen demuestra imagen radiopaca de la pelvis renal izquierda (pseudocoraliforme) (Fig. 2). El ultrasonido renal demuestra pérdida de la relación cortico-medular del riñón izquierdo, aumento del tamaño del riñón, heterogéneo, con ecos hipoecoicos y gas en su interior (absceso renal). La tomografía axial computarizada, demuestra absceso renal, riñón aumentado de tamaño (Fig. 3), y absceso intratorácico izquierdo. Se compensa a la paciente hemodinámicamente, y se le efectuó por la vía lumbar, lumbotomía izquierda. Los hallazgos de la cirugía fueron:

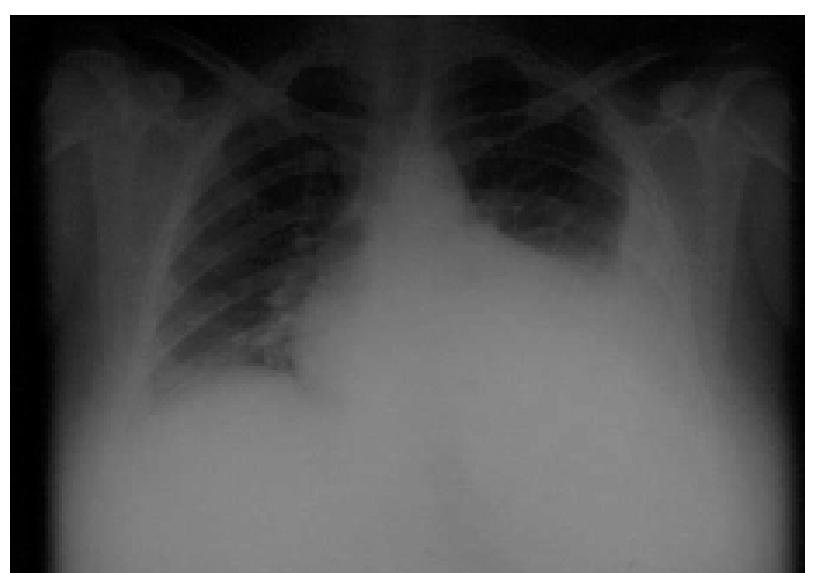

FIGURA 1: Radiografia de tórax, borramiento del seno costo diafragmático izquierdo.

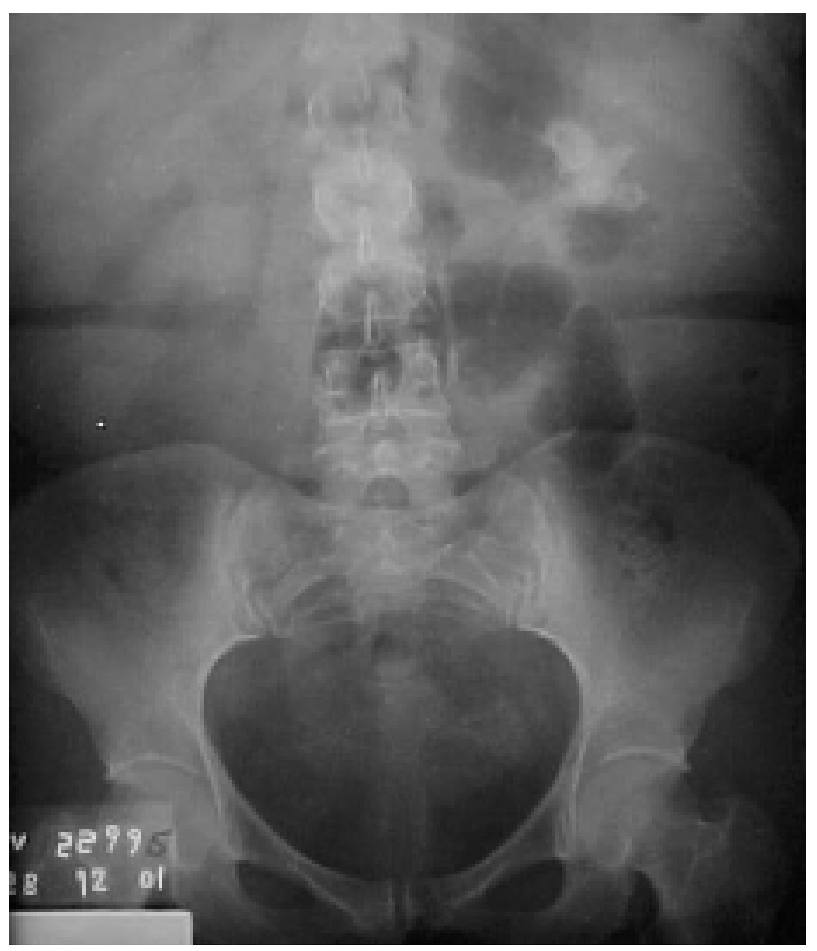

FIGURA 2: Radiografía de abdomen, cálculo renal.

1. Material purulento perirenal $500 \mathrm{cc}$.

2. Cálculo en pelvis y cáliz inferior.

3. Absceso subfrénico que infiltraba el bazo.

4. Empiema izquierdo con perforación diafragmática del lado izquierdo $500 \mathrm{cc}$.

El procedimiento que se efectuó fue: 1) drenaje del absceso perirenal; 2) nefrectomía izquierda; 3) drenaje del absceso subfrénico; 4) drenaje del absceso intrapleural y reparación diafragmática y colocación de tubo intratorácico. El curso de la paciente fue: mejora su estado general y hemodi- 


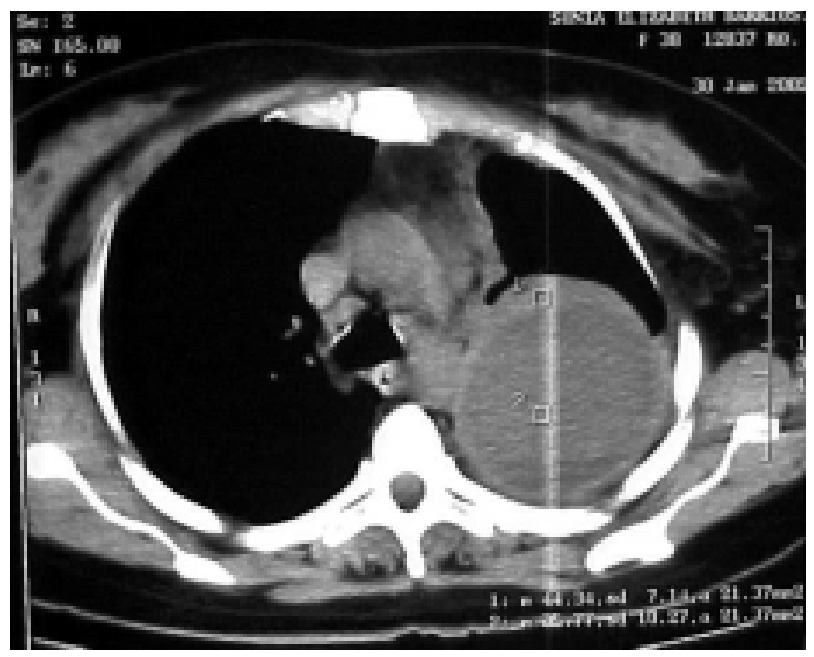

FIGURA 3: Tomografia de tórax, absceso en tórax.

námico, se retira previo control el tubo intratorácico al $7^{\circ}$ día. La paciente regresa en buenas condiciones. La anatomía patológica fue de pielonefritis xantogranulomatosa; 35 días después se le diagnostica por TAC un empiema loculado izquierdo por lo que se le efectuó 4 días después decorticación pulmonar izquierda. Nueve días después la paciente regresa bien, 30 días después la paciente tiene buena evolución, radiografía de tórax con buena evolución.

\section{DISCUSIÓN}

La obstrucción parcial y el reflujo de orina infectada pueden ocasionar el inicio de un absceso renal, o anteceder a la pielonefritis xantogranulomatosa que si se dejan que evolucionen espontáneamente pueden ocasionar pérdida renal. La asociación de reflujo y pielonefritis se ha establecido.

Más del $75 \%$ de los abscesos renales son causados por infecciones urinarias que comienzan en la vejiga, posterior a una cirugía urológica. $0,02 \%$ de las admisiones a hospitales son abscesos renales. $0,9-4 \%$ casos por 10.000 ingresos hospitalarios. La edad más afectada es a partir de los 40 años, y es más frecuente en el sexo femenino. La mortalidad es del $20-30 \%^{1,2}$. La pielonefritis xantogranulomatosa es una afección crónica poco frecuente, unilateral, raro bilateral, que afecta al riñón y en ocasiones a estructuras vecinas tales como las áreas perirenales, intrarenales, y muy poco frecuente a tórax ${ }^{1}$.
Entre los factores de riesgo están: la presencia de litiasis renal que bloquea el flujo urinario y sirve de reservorio para la infección, anormalidades del tracto urinario, estasis urinaria, cirugía urológica, biopsia renal, embarazo, drogadictos por la vía endovenosa, vejiga neurógena, trauma renal, hemodiálisis, y diabetes mellitus (un tercio de los pacientes) ${ }^{1-3}$.

El absceso puede romperse para el sistema pielocalicial o al espacio perinefrítico. Sólo en el primer caso hay infección de vías urinarias. Si no existe tratamiento el absceso se puede romper al retroperitoneo, o al peritoneo (colon), en este caso hubo infiltración del bazo, y menos frecuente se perfora a cavidad torácica ${ }^{4}$.

Los síntomas: dolor en el flanco o en el abdomen (69-87\%) con irradiación a la pierna, anorexia, malestar y pérdida de peso; puede ocurrir cistitis o síndrome miccional en el 33-44\%. Alguno de ellos tienen sudoración y escalofríos; más de la mitad de los pacientes tienen fiebre (64-83\%). En ocasiones los síntomas son vagos y el diagnóstico se suele hacer en la cirugía o en la necropsia ${ }^{3-5}$.

Signos y laboratorio: dolor abdominal, defensa a la palpación. Se puede palpar una masa en el flanco en el 37-54\%. El uro-análisis muestra células blancas y rojas, piuria, bacteriuria, el cultivo de orina puede mostrar el tipo de bacteria. La presencia de células blancas en la orina y fiebre con cultivos negativos de orina deben hacer sospechar la presencia de absceso renal, ya que en ocasiones no es evidente porque no se comunica con el sistema colector. Leucocitosis en el hemograma; los hemocultivos pueden ser positivos ${ }^{4,6}$.

Radiología: la diferencia entre pielonefritis y absceso renal es difícil. Se puede observar un riñón más grande, así como su silueta, y distorsión del contorno renal del lado afectado. Se puede observar obliteración del psoas con escoliosis hacia el lado afectado. Si el riñón está bien involucrado el nefrograma es difuso, diferido o ausente. Los cálices se ven mal definidos o amputados. En ocasiones la urografía excretora puede ser normal ya que involucra la porción anterior o posterior y no las vías. El TAC y el ultrasonido, ayudan para distinguir entre absceso y enfermedad inflamatoria. En el ultrasonido se puede observar una colección renal de líquido con ecos de baja densidad. 
El TAC es el procedimiento de elección, demuestra el absceso antes y después de aplicar el medio de contraste. Se puede observar un riñón agrandado, masa ecogénica, signo del anillo por incremento de vascularidad de las paredes del absceso o puede verse como un panal de abejas ${ }^{1}$.

Tratamiento: Se efectúa con antibióticos por la vía endovenosa, y el drenaje del absceso, si el absceso es pequeño y existe salida de pus por la orina, la colocación de un catéter doble "J" puede ser suficiente. La vía percutánea mediante aguja por donde se aspira la colección de líquido o pus, o la colocación de una nefrostomía es otra buena alternativa; sólo en los casos donde el drenaje no es adecuado o como sucedió en este caso donde la afectación era masiva es necesario la nefrectomía y drenar el absceso de las áreas involucradas ${ }^{1,6-9}$.

El pronóstico depende de lo pronto que se haga el diagnóstico y se efectúe el tratamiento, si la causa es un cálculo, éste se debe de extraer.

Complicaciones: infección renal continua, diseminación de la infección a otras zonas como en este caso al tórax, peritoneo, o retroperitoneo.

\section{CONCLUSIONES}

$\mathrm{El}$ absceso renal y/o pielonefritis xantogranulomatosa no son más que consecuencias de una infección urinaria no o mal tratada, o la dejadez de no tratar un cálculo renal en área pélvica, que puede tener serias consecuencias como la perforación a otras áreas como el tórax, la pérdida de una unidad renal, y la muerte.

\section{REFERENCIAS}

1. SANROMA I, GARRIDO MC, GARMENDIA JC, LÓPEZ JA, AROCENA F.: Pielonefritis xantogranulomatosa: a propósito de trece casos. Act Urol Esp 1989; 13 (2): 96-98.

2. ANDERSON KA, MCANINCH JW.: Renal abscess: classification and review of 40 cases. Urology 1980; 16: 333.

3. RIVES RK, HARTY JI, AMIN M.: Renal abscess: emerging concepts of diagnosis and treatment. J Urol 1980; 124: 446.

4. TUNDIDOR AM, BRENE D.: Absceso xantogranulomatoso del psoas 4 años después de nefrectomía por pielonefritis xantogranulomatosa. Arch Esp Urol 1993; 46 (5): 428-429.

5. CRONAN JJ, AMIS ES JR, DORFMAN GS.: Percutaneous drainage of renal abscesses. AJR 1984; 142: 351.

6. MEARES EM Jr.: Infecciones inespecíficas del aparato genitourinario. En Urología General de Smith. Editorial El Manual Moderno. 9 Edición. México 1989: 198.

7. HERRANZ F, LLEDÓ E, MONCADA F y cols.: Evolución de las pionefrosis tratadas mediante nefrostomías percutáneas. Valor de la técnica. Estudio de 118 casos. Act Urol Esp 1992; C-57.

8. GÓMEZ A, CORRAL J, BLÁZQUEZ J y cols.: Absceso renal y perirenal en pacientes adictos a la heroína (A.D.V.P.): aportación de cinco casos. Act Urol Esp 1992; P-108.

9. OCHOA O, CHÁVEZ R.: Absceso renal. Tratamiento médico. Arch Esp Urol 1991; 44 (3): 293-296.

Dr. E.A. Granados Loarca

31 Avda "F" 14-60 Zona 7

Cond. Villas de San Martín

Guatemala

(Trabajo recibido el 7 mayo de 2003) 